\title{
KEPUASAN PELANGGAN TERHADAP CITRA PERUSAHAAN DAN SWITCHING BARRIER SERTA DAMPAKNYA TERHADAP LOYALITAS PELANGGAN INDUSTRI JASA ASURANSI DI BALI
}

\author{
N. L. W. S. Telagawathi ${ }^{1}$, N. N. Yulianthini ${ }^{2}$ \\ 1,2 jurusan Manejemen, Universitas Pendidikan Ganesha, Singaraja \\ e-mail:wayan.sayang@undiksha.ac.id, ninymyulianthini@gmail.com
}

\begin{abstract}
Abstrak
Sebagai pengembangan dari penelitian yang dilakukan oleh Andres Kuusik, (2007), tujuan utama penelitian ini adalah untuk menguji secara empiris hipotesis-hipotesis tentang pengaruh kepuasan pelanggan, citra perusahaan, switching barrier, dan loyalitas pelanggan pada industri jasa asuransi. Penelitian ini menemukan bahwa loyalitas nasabah dari jasa asuransi dipengaruhi secara langsung oleh kepuasan pelanggan setelah melakukan pembelian. Sementara image/citra perusahaan dan switching barrier akan mempengaruhi loyalitas pelanggan jasa asuransi. Hasil lain juga menunjukkan bahwa konsistensi hubungan kepuasan pelanggan tidak menimbulkan konsumen untuk berpindah tetapi kepuasan pelanggan terhadap industri jasa asuransi mempunyai pengaruh yang signifikan terhadap loyalitas pelanggan. Hasil analisis tersebut berguna untuk menjelaskan hubungan yang terjadi di antara kepuasan pelanggan, terhadap image dan switching barrier serta hubungan antara kepuasan pelanggan, image dan switching barrier terhadap loyalitas pelanggan. Wawasan yang didasarkan pada hasil penelitian ini akan banyak membantu dalam memecahkan masalah dan pengambilan keputusan yang berkaitan dengan program pemasaran jasa, dan menerapkan strategi kualitas terbaik sebagai strategi kunci dalam menetapkan secara efektif dipasar Pengumpulan data dilakukan dengan menggunakan data primer, data primer diperoleh dengan kuesioner. Teknik sampling yang digunakan dengan purposive sampling, jumlah responden dalam penelitian sebanyak 185 nasabah asuransi di Bali, Model diuji dengan menggunakan two-step approach to structural equation modeling (SEM)
\end{abstract}

Kata kunci: kepuasan pelanggan, citra perusahaan, switching barrier, loyalitas pelanggan, structural equation modeling (SEM)

\begin{abstract}
As the development of the research made by by Andres Kuusik,(2007), the primary purpose of this research is to examine as an empirical hipothesis- the hipothesis is about the effect of the customer statisfaction, the image of the corporation, switching barrier, and the loyality of the customer with the insurance. This research found that the loyality of the customer of insurance service directly affected by the consumer's statisfaction after did the purchase. Meanwhile the image of the corporation and switching barrier will affect the loyality of the consumer of the insurance service. The other results show the consistency of the relation of the statisfaction of the consumer will not make the consumer to move but the statisfaction of the consumer of the insurance services industry has the significant influence with loyality of the consumer. The result of the analisis will explain the relationship between the statisfaction of the consumer with image and switching barrier and also the relationship between the statisfaction of the consumer ,image and switchin barrier with the loyality of the consumer. Insights based on the result of this study will helpful in solving proble,s and making decisions related to the program marketing services, the best strategy as the key strategy to be applied effectively in the market place. The collect data will be held with data primer, and the data primer collected by quitioner. Sampling technic used with puposive sampling, the respondent in this research will be 200 customers of insurance in Bali. The Model will be examined by using two-step approach to structural equation modeling (SEM).
\end{abstract}

Keywords: customer statisfaction, the image of the corporation, switching barrier, the loyalty of the consumer, structural equation modeling (SEM).

\section{Pendahuluan}

Semakin tingginya tingkat persaingan bisnis, telah mengalihkan perhatian banyak perusahaan penyedia jasa (service provider) untuk lebih menekankan pada upaya 
mempertahankan pelanggan daripada mengakuisisi pelanggan baru. Mempertahankan pelanggan yang sudah ada memerlukan biaya pemasaran seperlima kali lipat dibandingkan biaya pemasaran untuk memperoleh pelanggan baru. Selain itu mempertahankan pelanggan setia atau loyal juga terbukti, dapat meningkatkan laba bagi perusahaan. Keadaan ini menuntut manajemen perusahaan atau unit-unit usaha untuk dikelola lebih efektif dan efisien agar dapat memenangkan persaingan, demikian halnya dalam industri asuransi .

Pertumbuhan dan perkembangan industri asuransi suatu negara tentunya melalui berbagai tahap yang masing-masing mempunyai ciri yang berbeda ditinjau dari segi kondisi perekonomian, sifat dan peluang usaha, harapan dan tuntutan masyarakat akan komitmen perusahaan untuk memenuhi kewajibannya. Tahap-tahap yang dimaksud lazimnya dimulai dengan tahap konsolidasi dan reorientasi diikuti dengan tahap penyehatan dan pengembangan, yang selanjutnya ditingkatkan untuk mengarah kepada tahap pengembangan lebih lanjut yang dilandasi oleh sikap inovatif yang berorientasi kepada kebutuhan masyarakat, serta diwarnai iklim kompetisi yang berbeda dengan periode sebelumnya (Danusaputro dan Sullahi, 1995).

Perkembangan industri asuransi di Indonesia sejak dilaksanakan deregulasi dapat diperkirakan bahwa situasi dan kondisi bisnis industri asuransi pada masa mendatang akan semakin kompetitif. Hal ini sudah tentu merupakan proses pendewasaan dari industri asuransi Indonesia ke arah profesionalisme, karena dilaksanakan melalui penciptaan iklim bersaing yang wajar antar perusahaan asuransi di Indonesia baik asuransi dalam negeri maupun asuransi asing (Anggadireja dan Djajamiharja, 1993). Persaingan menjadi semakin ketat setelah asuransi asing turut memperebutkan nasabah pada pasar yang sama. Asuransi asing ini mempunyai kelebihan dalam hal nama besar yang mendunia, pilihan produk yang inovatif, serta jaringan global. Situasi ini menggambarkan betapa ketatnya persaingan untuk meraih pangsa pasar yang lebih luas.

Hal ini sejalan dengan apa yang dinyatakan Lovelock (2004) bahwa sektor jasa merupakan sektor yang paling besar mengalami perubahan akibat dari cepatnya perubahan yang dialami oleh faktor lain, seperti perubahan teknologi yang secara langsung menaikkan iklim kompetisi di dalam industri. Karena itu para pengelola industri asuransi berusaha untuk memberikan kepuasan yang terbaik kepada nasabahnya. Selain sisi teknologi, perusahaan asuransi dan para pemasar juga berlomba untuk memodifikasi strategi pemasaran. Mereka semakin mengerti bahwa pelanggan adalah penting bagi kehidupan perusahaannya. Pelanggan harus tetap dijaga dan dipertahankan agar tidak berpaling ke perusahaan lain. Perusahaan asuransi harus menciptakan strategi pemasaran yang mampu memberi sentuhan pelayanan personal dengan menciptakan komunikasi dua arah dengan membangun dan mengelola hubungan jangka panjang yang saling menguntungkan dengan para pelanggan (relationship marketing).

Kepuasaan pelanggan merupakan evaluasi purnabeli setelah alternatif yang dipilih sekurang-kurangnya memberikan hasil sama atau melampui harapan pelanggan (Engel, 1990). Kepuasan pelanggan merupakan tingkat perasaan seseorang setelah membandingkan kinerja atau hasil yang dia rasakan dibanding harapannya (Kotler, 2000). Ketidakpuasan timbul apabila hasil yang diperoleh tidak memenuhi harapan pelanggan. Kepuasan pelanggan akan mempengaruhi citra perusahaan dan switching barrier (Mardalis, 2005). Di samping itu kepuasan pelanggan akan mempengaruhi perilaku untuk membeli kembali jasa dari penyedia jasa yang sama (Woodside, Frey dan Daily, 1989). Menurut Oliver (1999) bentuk sikap konsumen terhadap penyediaan jasa berdasarkan harapan sebelumnya tentang kinerja perusahaan dan sikap ini berpengaruh pada loyalitas pelanggan. Beberapa Penelitian terdahulu mengenai loyalitas pelanggan hanya memasukkan kepuasan konsumen sebagai penentu terciptanya loyalitas, misalnya penelitian dari Anderson, et al. (1996) hanya mempertimbangkan satu-satunya kepuasan pelanggan sebagai penentu loyalitas. Atau penelitian Caruana, (2002) bahwa kepuasan pelanggan merupakan faktor mediasi yang menghubungkan antara kualitas 
pelayanan dan loyalitas, artinya kualitas layanan secara positif mempengaruhi loyalitas melalui kepuasan konsumen.

Penelitian ini mengacu pada penelitian Andres Kuusik, (2007) tidak seperti penelitian sebelumnya bahwa kepuasan pelanggan bukan satu-satunya faktor terciptanya loyalitas pelanggan. Dengan menguji dua variabel yang belum diuji dalam penelitian Anderson, et al. (1996) yaitu, switching barrier dan citra perusahaan (company image). Sebagaimana diketahui bahwa kepuasan pelanggan bukan satu-satunya faktor terciptanya loyalitas pelanggan. Tingkat kepuasan konsumen yang tinggi belum tentu menghasilkan pembelian ulang dan peningkatan penjualan, hal ini sesuai dengan penemuan Griffin (2003). Berbeda dengan kepuasan pelanggan yang sudah sangat terkenal dan dibuat modelnya oleh Zeithalm et al. (1990), maka loyalitas pelanggan ini belum ada model yang dapat diterima secara luas. Pengaruh citra perusahaan atas pelanggan dalam penelitian Bloomer, et al. (1998) yang menyimpulkan bahwa citra tidak memberi dampak langsung kepada loyalitas pelanggan, namun menjadi variabel moderator antara kualitas dan loyalitas pelanggan.

Nguyen (2001) membuktikan dalam penelitiannya bahwa citra perusahaan positif mempengaruhi loyalitas pelanggan pada tiga sektor (telekomunikasi, ritel dan pendidikan). Aydin (2005) menjelaskan bahwa citra perusahaan berasal dari suatu fungsi pengalaman konsumsi konsumen dan kepuasan pelanggan secara langsung mempengaruhi persepsi terhadap perusahaan atau citra perusahaan. Hal ini serupa juga diungkapkan oleh Anddreassen dan Lindestand (1998) yang menekankan bahwa citra perusahaan berpengaruh kepada kinerja persepsi kualitas, kepuasan konsumen dan loyalitas pelanggan. Faktor lain yang mempengaruhi loyalitas pelanggan adalah switching barrier. Dengan demikian, rumusan masalah yang di angkat dalam penelitian ini sebagai berikut: 1) Bagaimana pengaruh kepuasan pelanggan (customer satisfaction) terhadap citra perusahaan (company image), 2) Bagaimana pengaruh kepuasan pelanggan (customer satisfaction) terhadap switching barrier. 3) Bagaimana pengaruh kepuasan pelanggan (customer satisfaction) terhadap loyalitas pelanggan (customer loyalty) 4) Bagaimana pengaruh citra perusahaan (company image) terhadap loyalitas pelanggan (customer loyalty) 5) Bagaimana pengaruh switching barrier terhadap loyalitas pelanggan (customer loyalty).

Penelitian ini bertujuan untuk: 1) Untuk menguji pengaruh kepuasan pelanggan terhadap citra perusahaan, 2) Untuk menguji pengaruh kepuasan pelanggan terhadap switching barrier, 3) Untuk menguji pengaruh kepuasan pelanggan terhadap loyalitas pelanggan, 4) Untuk menguji pengaruh citra perusahaan terhadap loyalitas pelanggan, 5) Untuk menguji pengaruh switching barrier terhadap loyalitas pelanggan.

Pengembangan hipotesis penelitian ini adalah: 1) Pengaruh kepuasan pelanggan (customer satisfaction) terhadap citra perusahaan (company image). Karena kunci utama untuk memenangkan persaingan adalah memberikan kepuasan kepada pelanggan melalui penyampaian produk dan jasa yang berkualitas dengan harga yang bersaing. pentingnya citra sebagai sarana atau alat untuk meraih keunggulan bersaing di pasar. Begitu perusahaan telah secara jelas mendefinisikan citranya kepada pelanggan, maka langkah berikutnya adalah mengkomunikasikan citra tersebut agar elemen ini menjadi sumber keunggulan bersaing yang perusahaan miliki dalam jangka panjang. Kepuasan pelanggan sebagai pengharapan atau ekspektasi pelanggan dibentuk oleh pengalaman masa lalunya, pembicaraan dari mulut ke mulut, dan promosi yang dilaku kan perusahaan jasa akan membentuk sikap positif konsumen terhadap perusahaan, yang nantinya bisa membangun citra perusahaan yang tinggi (Kotler, 2000). Aydin (2005) menjelaskan bahwa citra perusahaan berasal dari suatu pengalaman konsumsi konsumen, dan kepuasan pelanggan adalah fungsi dari pengalaman konsumsi ini, karenanya kepuasan pelanggan secara langsung mempengaruhi persepsi terhadap citra perusahaan. Hal serupa juga dikemukakan oleh Anddreassen dan Lindestand (1998) yang menekankan bahwa citra perusahaan berpengaruh kepada kepuasan pelanggan dan loyalitas pelanggan. Berdasarkan uraian tersebut di atas, maka dapat dirumuskan hipotesis sebagai 
berikut: H1: Kepuasan konsumen (customer satisfaction) berpengaruh terhadap citra perusahaan (company image)

Hipotesis ke- 2) Pengaruh kepuasan pelanggan (customer satisfaction) terhadap switching barrier Kepuasan pelanggan sebagai respon terhadap kebutuhan konsumen yang merupakan pertimbangan terhadap suatu produk atau jasa dalam menyediakan tingkat konsumsi yang menyenangkan (Zeithaml, 1998). Sedangkan Kotler (2000) mendefinisikan kepuasan pelanggan adalah tingkat perasaan seseorang setelah membandingkan kinerja atau hasil yang dia rasakan dibandingkan harapannya. Kepuasan pelanggan akan membawa dampak pada perilaku konsumen (Assael, 1998). Pelanggan yang puas cenderung enggan untuk melakukan perpindahan merek, selama produk yang dipakai bisa memenuhi semua kebutuhan dan harapannya. Biarpun merek lain itu memberikan fitur atau manfaat yang lebih dari merek yang sudah biasa dikonsumsinya. Berdasarkan uraian di atas maka dapat dirumuskan hipotesis sebagai berikut: H3: kepuasan pelanggan (customer satisfaction) berpengaruh terhadap switching barrier

Hipotesis ke-3 yaitu Pengaruh kepuasan pelanggan (customer satisfaction) terhadap loyalitas pelanggan (customer loyalty). Ketika pelanggan membeli suatu produk atau jasa, kemudian ia puas terhadap produk tersebut, maka ia akan mengalami kepuasan pelanggan. Namun hal tersebut tidak langsung menjadikannya setia. Perusahaan harus dapat memberikan perbaikan kualitas yang terus menerus supaya dapat mempertahan pelanggan dan mereka terus loyal. Berdasarkan penelitian Bowen (2001) terdapat hubungan antara loyalitas pelanggan dan kepuasan pelanggan walaupun hubungan bersifat nonlinier dan asimetrik. Kesetiaan pelanggan, sangat dipengaruhi oleh kepuasan pelanggan, dimana kepuasan pelanggan merupakan satu kunci dalam membangun sebuah kesetiaan pelanggan. Schnaars (1991), pada dasarnya tujuan dari suatu bisnis adalah untuk menciptakan para pelanggan merasa puas. Terciptanya kepuasan pelanggan dapat memberikan beberapa manfaat, diantaranya hubungan anatara perusahaan dan pelanggan menjadi harmonis, memberikan dasar yang baik bagi pembelian ulang dan terciptanya loyalitas pelanggan, menyatakan hal positif tentang perusahaan, tetap loyal pada perusahaan, merekomendasikan perusahaan pada orang lain dan meningkatkan volume pembelian atau bersedia membayar harga premium. Atau penelitian yang dilakukan oleh Anderson et al., (1996) semakin tinggi kepuasan pelanggan akan menyebabkan komitmen seseorang untuk cenderung loyal kepada perusahaan. Melihat hubungan tersebut maka dalam penelitian ini dikemukakan hipotesis yang ketiga: H3: Kepuasan pelanggan (customer satisfaction) berpengaruh terhadap loyalitas pelanggan (customer loyalty).

Hipotesis ke- 4 adalah Pengaruh citra perusahaan (company image) terhadap loyalitas pelanggan (customer loyalty). Citra perusahaan adalah faktor yang mempengaruhi penciptaan loyalitas pelanggan. Perusahaan yang mampu memberikan kesan yang berarti bagi konsumen akan lebih mudah mendapat perhatian khusus dari konsumen. Dalam persaingan yang semakin ketat mendorong perusahaan untuk lebih memfokuskan pada upaya untuk mempertahankan pelanggan yang ada. Untuk dapat bertahan dalam lingkungan bisnisnya, salah satunya dengan menguatkan citra perusahaan dan membangun, memelihara serta mempertahankan kepercayaan pelanggan sehingga tercipta loyalitas pelanggan. Mempertahankan konsumen yang loyal sangat penting dalam memenangkan persaingan pasar. Serupa dengan pendapat tersebut, Nguyen (2001) membuktikan dalam penelitiannya bahwa citra perusahaan positif mempengaruhi loyalitas pelanggan. Hal ini juga didukung oleh penelitian Anddreassen dan Lindestand (1998) yang menekankan bahwa citra perusahaan akan berdapam pada loyalitas pelanggan. Berdasarkan uraian di atas, maka dapat dirumuskan hipotesis sebagai berikut: $\mathrm{H} 4$ : Citra perusahaan (company image) berpengaruh terhadap loyalitas pelanggan (customer loyalty).

Hipotesis ke- 5 adalah pengaruh switching barrier terhadap loyalitas pelanggan (customer loyalty). Consumer characteristic adalah karakter konsumen yang mempengaruhi tingkat loyalitas seseorang. Karena latar belakang dan pengalaman konsumen yang berbeda- 
beda, biasanya nilai-nilai dan kenyakinan yang mereka pahami pun tidak sama. Ada kelompok konsumen yang loyal, ada pula konsumen yang cenderung berpindah-pindah merek, tidak peduli dengan pertimbangan kebutuhan, manfaat lebih atau resiko yang diterimanya. Switching barrier menyangkut hambatan yang dirasakan konsumen bila konsumen berpindah dari satu merek ke merek yang lain. Hambatan ini tidak hanya berdasarkan pertimbangan nilai-nilai ekonomis, melainkan juga berkaitan dengan faktor psikologis, sosial, fungsional dan ritual. Switching barrier lebih banyak dipengaruhi oleh faktor eksternal produk itu sendiri, karakter konsumen yang tidak suka berpindah-pindah merek selama produk yang dipakai bisa memenuhi semua kebutuhan dan harapannya. Biarpun merek lain itu memberikan fitur atau manfaat yang lebih dari merek yang sudah biasa dikonsumsinya, konsumen tidak peduli (kotler, 2000). Seringkali pelanggan tidak merasa puas dengan jasa yang diterima, Namun karena biaya berpindah yang dirasakan pelanggan cukup besar apabila berpindah ke perusahaan lain, maka konsumen tetap menjadi pelanggan yang setia. Berdasarkan uraian di atas maka dapat dirumuskan hipotesis sebagai berikut: H5: switching barrier berpengaruh terhadap loyalitas pelanggan (customer loyalty)

\section{Metode}

Penelitian ini dirancang untuk memperoleh data tentang pengaruh ,kepuasan pelanggan, citra perusahaan, switching barrier dan loyalitas pelanggan pada industri asuransi di Bali. Metode pengambilan sampel dalam penelitian ini menggunakan nonprobabilistic sampling dengan purposive sampling, yaitu setiap elemen dalam populasi tidak memiliki probabilitas yang sama untuk dipilih menjadi sampel atau pemilihan anggota sampel dilakukan dengan tidak acak dan bersifat subyektif (Sekaran, 1992: 235-244). Jumlah sampel yang diperlukan untuk pengujian model dengan menggunakan SEM adalah berkisar antara 100-200 (Hair et al., 1998 : 604-605). Sebagaimana rekomendasi Hair et al., (1998), maka jumlah sampel maksimum yang digunakan adalah 185 sampel dengan penyebaran sampel sebanyak 230 sampel. Penelitian ini menggunakan metoda survey. Data primer yang dikumpulkan dengan melakukan penyebaran kuesioner oleh peneliti secara langsung.

Pada penelitian ini terdapat tiga variabel endogen yaitu citra perusahaan (company image), hambatan berpindah (switching barriers) dan loyalitas pelanggan (customer loyalty) serta satu variabel eksegenous yaitu kepuasan pelanggan (customer loyalty). Seluruh Indikator yang digunakan dalam variable tersebut menggunakan indikator yang diadopsi dari Andres Kuusik (2007), diukur dengan menggunakan Skala Likert 5 poin, dari sangat setuju-sampai sangat tidak setuju.

Pada penelitian ini hipotesis yang diajukan akan diuji dengan Structural Equation Modeling (SEM) merupakan tehnik multivariate yang mengkombinasikan aspek regresi berganda dan analisis faktor untuk mengestimasi serangkaian hubungan ketergantungan secara simultan (Hair et al., 1998: 583). Pada penelitian ini, menggunakan pendekatan SEM dua tahap (two-step approach to SEM) akan dilakukan untuk menguji model struktural yang diajukan. Pada pendekatan SEM dua tahap, model pengukuran terlebih dahulu diestimasi, kemudian ditetapkan pada tahap kedua ketika model struktural diestimasi (Anderson \& Gerbing seperti dikutip dalam Purwanto, 2002).

Setelah pengujian model pengukuran dilakukan, pengujian berikutnya yaitu menguji goodness -of fit yang mengukur derajat kesesuaian antara model yang dihipotesiskan dengan data yang disajikan. Pendekatan SEM dua tahap (two-step approach to SEM) dilakukan untuk menguji model struktural yang diajukan seperti terlihat pada Gambar 1. Pada pendekatan SEM dua tahap, model pengukuran terlebih dahulu diestimasi, kemudian ditetapkan pada tahap kedua ketika model struktural diestimasi (Anderson \& Gerbing seperti dikutip dalam Purwanto, 2002) Pada penelitian ini, maximum likehood estimation (MLE) digunakan untuk menguji parameter-perameter model dengan nilai rata-rata data mentah sebagai input. 


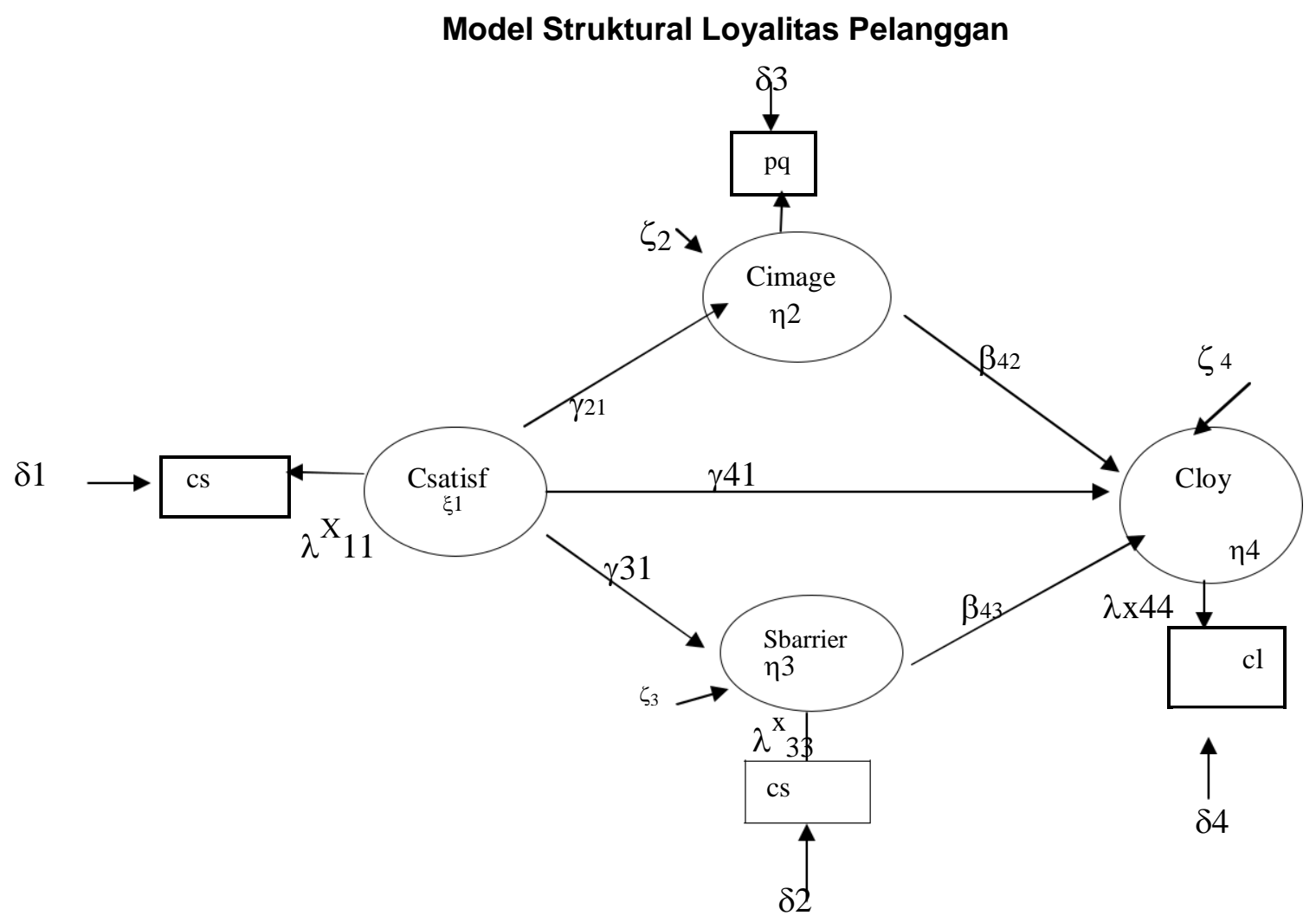

\section{Hasil dan Pembahasan}

Pada penelitian ini, pengujian goodness-of-fit model struktural atau model keseluruhan dilakukan pada tipe kesesuaian yaitu absolute fit measures, incremental of fit measures, dan parasimonious fit measures. Tipe yang pertama yaitu absolut fit measures mengukur tingkat dimana model secara keseluruhan memprediksi matriks kovarians atau korelasi yang di observasi. Pada penelitian ini, pengujian absolute fit measures dilakukan dengan indeks kesesuaian chi-square statistik (c atau CMIN), GFI dan RMSEA. Tipe kedua yaitu incremental fit measures membandingkan antara model yang diajukan dengan model dasar yang biasa disebut null model. Pada penelitian ini, pengujian incremental fit measures dilakukan dengan indeks kesesuaian AGFI dan CFI. Tipe ketiga yaitu parsimonious fit measures menghubungkan tingkat kesesuaian model dengan jumlah koefisien yang diestimasi untuk memperoleh tingkat kesesuaian tersebut. Pada penelitian ini, pengujian parsimonius fit measures dilakukan dengan indeks kesesuaian normed chi-square (CMIN/DF).

Pengujian model struktural pertama yang dilakukan yaitu model struktural yang dihipotesiskan dengan menggunakan alat analisis statistik AMOS 6 dengan jumlah data 190 . Hasil dari output pengujian model struktural didapatkan indeks-indeks kesesuaian dan hubungan antar variabel seperti terlihat pada Tabel 1. Adapun model struktural yang merupakan model asli yang diusulkan dapat dilihat pada Gambar 1. 
Gambar 1. Hasil Pengujian Model Struktural

Goodness-of-fit

\begin{tabular}{|c|c|c|c|c|}
\hline $\begin{array}{l}\text { TipeGoodness-c } \\
\text { fit }\end{array}$ & $\begin{array}{l}\text { f- Indeks } \\
\text { TipeGoodness-of-fit }\end{array}$ & Cut-off value & Hasil model & Keterangan \\
\hline $\begin{array}{l}\text { Absolut } \\
\text { measures }\end{array}$ & $\begin{array}{l}\text { fit } \chi^{2} \text { statistic }(\mathrm{CMIN}) \\
\text { Prob. } \chi^{2} \\
\text { GFI } \\
\text { RMSEA }\end{array}$ & $\begin{array}{l}\text { Diharap kecil } \\
\geq 0.05 \\
\geq 0.90 \\
\leq 0.08\end{array}$ & $\begin{array}{l}10.610 \\
0.062 \\
0.970 \\
0.061\end{array}$ & $\begin{array}{l}\text { Baik } \\
\text { Baik } \\
\text { Baik }\end{array}$ \\
\hline $\begin{array}{l}\text { Incremental } \\
\text { measures }\end{array}$ & $\begin{array}{c}\text { fitAGFI } \\
\text { CFI } \\
\text { TLI }\end{array}$ & $\begin{array}{l}\geq 0.90 \\
\geq 0.94 \\
\geq 0.95\end{array}$ & $\begin{array}{l}0.941 \\
0.912 \\
0.776\end{array}$ & $\begin{array}{l}\text { Baik } \\
\text { Baik } \\
\text { marginal }\end{array}$ \\
\hline $\begin{array}{l}\text { Parsimonious } \\
\text { measures }\end{array}$ & fitNormed $\chi^{2}(\mathrm{CMIN} / \mathrm{DF})$ & $\leq 2.00$ & 1.981 & Baik \\
\hline \multicolumn{5}{|c|}{ Hubungan antar variabel } \\
\hline Hipotesis & Hubungan & $\begin{array}{l}\text { Unstandardized } \\
\text { Estimate }\end{array}$ & C.R. & $\begin{array}{l}\text { Standardized } \\
\text { Estimate }\end{array}$ \\
\hline$\overline{\mathrm{H} 1}$ & Cimage $<\ldots . . . . \quad$ csatisf & 0.270 & $2.379^{* *}$ & 0.220 \\
\hline $\mathrm{H} 2$ & 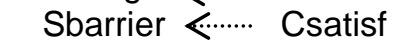 & f 0.174 & $2.130^{* *}$ & 0.200 \\
\hline H3 & Cloy $\quad \ldots \ldots .$. Csatisf & 0.298 & $2.216^{* *}$ & 0.254 \\
\hline $\mathrm{H} 4$ & ※.... Clmage & e 0.287 & $3.254^{* \star *}$ & 0.279 \\
\hline $\mathrm{H} 5$ & <..... Cbarrier & 0.291 & $2.014^{\star *}$ & 0.691 \\
\hline
\end{tabular}

* signifikan pada tingkat signifikansi $(\alpha) 10 \%$

"signifikan pada tingkat signifikansi $(\alpha) 5 \%$

*** signifikan pada tingkat signifikansi $(\alpha) 1 \%$

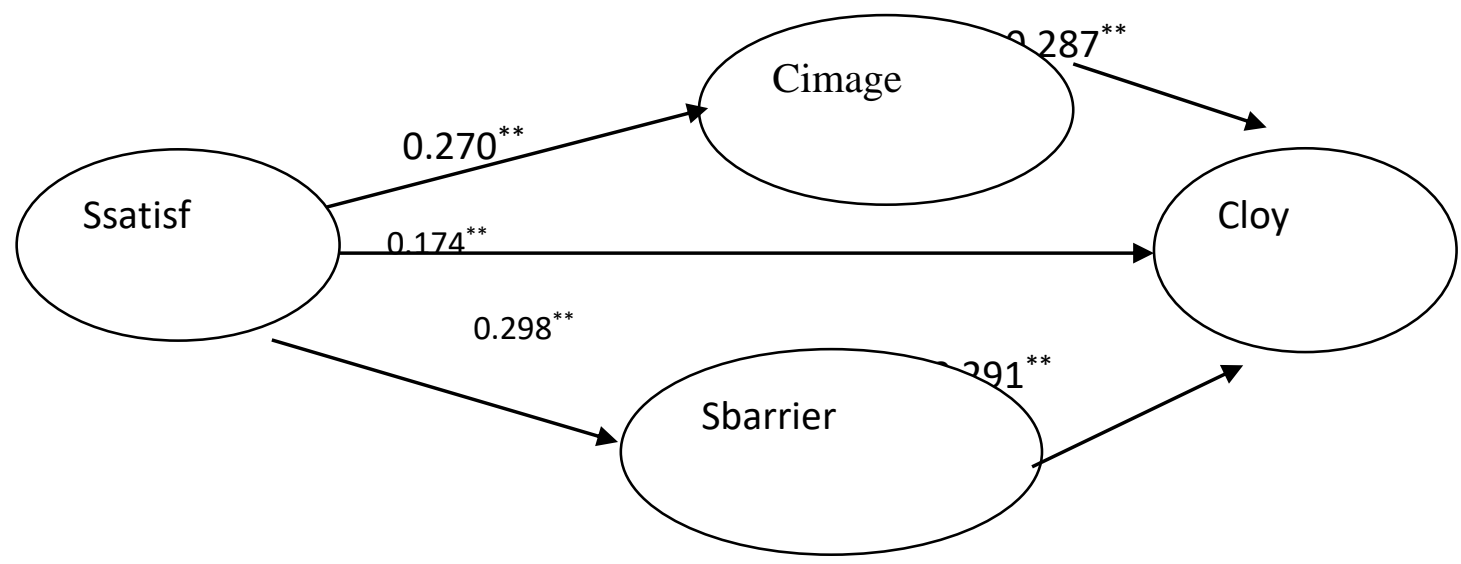

Gambar 2: Model struktural hasil pengujian

Seperti terlihat pada Tabel 1, nilai $c^{2}$ (Chi-Square) sebesar 10.610 dengan tingkat signifikansi 0.01 menunjukkan bahwa hipotesis nol yang menyatakan bahwa tidak terdapat perbedaan matriks kovarians sampel dan matrik kovarians populasi yang diestimasi tidak dapat ditolak. Dengan demikian secara statistik dapat diterima atau dengan kata lain merupakan model yang baik.

Indeks-indeks goodness-of-fit lain seperti RMSEA, GFI, relative $\mathrm{c}^{2}$ (CMIN/DF), TLI dan $\mathrm{NFI}$, AGFI menunjukkan nilai kesesuaian yang baik pada model, karena nilai indeksnya memenuhi persyaratan nilai kritis yang ditetapkan. Walaupun model sudah menunjukkan goodness-of-fit yang secara statistik bisa diterima. Hasil pengujian model struktural 1 menunjukkan nilai degree of fredom sebesar 6 sehingga hubungan antar variabel akan 
signifikan pada tingkat signifikansi (a) $1 \%$ apabila mempunyai nilai C.R. lebih besar atau sama dengan 3,143 (C.R. ${ }^{3}$ 3,143), sedangkan signifikan pada tingkat signifikansi (a) 5\% apabila mempunyai nilai C.R. lebih besar atau sama dengan 1,943 (C.R. ${ }^{3} 3,143$ ), dan signifikan pada tingkat signifikansi (a) 10\% apabila mempunyai nilai C.R. lebih besar atau sama dengan 1,440 (C.R. $\left.{ }^{3} 1,440\right)$.

Setelah pengujian goodness-of-fit model struktural dapat diterima, tahap berikutnya adalah pengujian hipotesis yang diajukan dengan mengevaluasi arah dan tingkat signifikansi hubungan kausalitas antar variabel yang ada didalam model penelitian. Pengujian hipotesis atau hubungan kausalitas antar variabel dalam model struktural dilakukan dengan melihat arah dan signifikansinya.

Dalam penelitian ini, pengujian hubungan kausalitas antar variabel dilakukan dengan uji satu sisi pada tingkat signifikansi (a) sebesar 1\%, 5\%, hingga maksimum 10\%. Hal ini didasarkan pada pernyataan Hair et al., (1998) yang menyebutkan bahwa penentuan nilai kritis tergantung pada penentuan teoritis mengenai hubungan yang diprediksi. Apabila hubungan positif atau negatif dihipotesiskan, pengujian signifikansi satu arah dapat dilakukan.

Analisis mengenai arah dan tingkat signifikansi hubungan antar variabel yang dihipotesiskan didasarkan pada hasil pengujian model struktural 1. Hasil pengujian model struktural 1 menunjukkan nilai degree of fredom sebesar 6 sehingga hubungan antar variabel akan signifikan pada tingkat signifikansi (a) 1\% apabila mempunyai nilai C.R. lebih besar atau sama dengan 3,143 (C.R. ${ }^{3} 3,143$ ), sedangkan signifikan pada tingkat signifikansi (a) $5 \%$ apabila mempunyai nilai C.R. lebih besar atau sama dengan 1,943 (C.R. ${ }^{3} 3,143$ ), dan signifikan pada tingkat signifikansi (a) 10\% apabila mempunyai nilai C.R. lebih besar atau sama dengan 1,440 (C.R. ${ }^{3}$ 1,440). Hasil penelitian ini menemukan kepuasan pelanggan akan terciptanya loyalitas pelanggan. Pelanggan yang puas akan mebuat citra perusahaan menjadi baik dimata pelanggan dan kecendrungan untuk berpindah menjadi rendah, image perusahaan yang baik akan menciptakan pelanggan yang loyal. Penelitian ini sejalan dengan penelitian yang dilakukan oleh Nguyen (2001) membuktikan dalam penelitiannya bahwa citra perusahaan positif mempengaruhi loyalitas pelanggan pada tiga sektor (telekomunikasi, ritel dan pendidikan). Aydin (2005) menjelaskan bahwa citra perusahaan berasal dari suatu fungsi pengalaman konsumsi konsumen dan kepuasan pelanggan secara langsung mempengaruhi persepsi terhadap perusahaan atau citra perusahaan. Hal ini serupa juga diungkapkan oleh Anddreassen dan Lindestand (1998) yang menekankan bahwa citra perusahaan berpengaruh kepada kinerja persepsi kualitas, kepuasan konsumen dan loyalitas pelanggan. Faktor lain yang mempengaruhi loyalitas pelanggan adalah switching barrier.

\section{Simpulan dan Saran}

Penelitian ini menguji sebuah model yang melukiskan hubungan antar variable yang dihipotesiskan dari kepuasan pelangggan, company image, dan switching barrier dapat mempengaruhi loyalitas pelanggan industry jasa asuransi. Hasil penelitian ini menunjukkan bahwa kepuasan pelanggan akan menimbulkan komitmen untuk tetap loyal, komitmen perusahaan untuk selalu menepati janji, mengurangi pelanggan berpindah pada merek yang lain.

Citra perusahaan/image dari perusahaan asuransi memiliki pengaruh positif dan signifikan. Citra yang baik menjadi pertimbangan konsumen ketika konsumen akan melakukan pembelian atau akan menjadi nasabah pada perusahaan asuransi. Image perusahaan akan menjadi pertimbangan yang baik dalam menciptakan loyalitas pelanggan yang nantinya berdampak komitmen untuk tetap menggunakan jasa sama kembali.

Pelanggan yang puas akan mengurangi perpindahan merek, switching barrier mempunyai hubungan yang positif terhadap loyalitas pelanggan, kemungkinan pelanggan tidak melakukan perpindahan pada merek, karena ada resiko yang ditanggung konsumen ketika melakukan perpindahan merek. Hasil ini konsisten dengan Anderson et al., (1996). 


\section{Daftar Pustaka}

Andreassen W (1997), Customer Loyalty and complex Service : The Impact Of Corporate image on Quality, Customer Satisfaction and Loyalty For Customers With Varying Degrees OF service Expertise. Journal Of Service industry, Vol 8, No 4

Anderson, E. W., Fornell, C., Johnson, D. M., Cha, J. and Bryant, E. B (1996), “ The American Customer Satisfaction Index: Nature, Purpose, and Findings", Journal of Marketing, Vol. 60, October, pp. 7-18

Anggadiredja, Dedi dan Didi Djajamihardja, 1993, Salesmanship untuk Perbankan I, Jakarta: Institut Bankir Indonesia

Aydin, S. and Ozer, G., (2005), The Analysis Of Antecedents Of Customer Loyalty In The Turkish Mobile Telecommunication Market, European Journal Of Marketing, Vol. 39 No 7, pp. 910-125.

Bloomer, J., Ruyter, k., And peeters p (1998) Investigating Drives of Bank loyalty : theComplex Relationship between image, Service Quality and Satisfaction, the International Journal Of bank Marketing. Vol 16, no 7 pp 276.

Hair, Joseph F., Jr., Rolph E. Anderson, Ronald L. Tatham, and William C. Black (1998), Multivariate data Analysis, 5 th ed., Upper Saddle River, NJ: Prentice-Hal, Inc.

Kuusik, Andres. (2007). Affecting Customer Loyalty: Do Different Factors Have Various Influences In Different Loyalty Levels? University of Tartu, Faculty of Economics and Business Administration,

Lovelock, C. (1994), Product Plus. New York: McGraw-Hill, Inc.

Lovelock, Christopher; Jochen Wirtz; Hean Tat Keh; Xiongwen Lu. (2005), Services Marketing, People, Technology, Strategy. 2nd Edition, Pearson-Prentice Hall, Singapore

Mardalis, Ahmad (2005), Meraih Loyalitas Pelanggan, Jurnal Bisnis dan Manajemen Universitas Muhamadiah solo (Benefit), Vol 9, N0 2, pp 111-118.

Mueller, Ralph O. (1996), Basic Principles of Structural Equation Modeling: An Introduction to LISREL, and EQS, New York: Spinger-Verlag New York, Inc.

Nguyen, N. And Leblanc, G. (2001), The Mediating Role Of Corporate Image On Customers' Retention Decisions : An Investigating In Financial Service. The International Journal of Marketing, Bradford. Vol 16, pp 52.

Purwanto, B.M (2002), "The effect of Salesperson Stress Factors on Job performance", Journal Ekonomi dan Bisnis Indonesia, Vol 17, No. 2, 150-169.

Sekaran, Uma (1992), Research Methods for Business, $2^{\text {th }}$ eds., New York, USA: John Wiley \& Sons Inc. 